\title{
COLLABORATIVE LEARNING AND INDIVIDUAL WORK PERFORMANCE IN COWORKING SPACES
}

\author{
Kolja OSWALD $\mathbb{1}^{*}$, Xiaokang ZHAO* \\ Glorious Sun School of Business and Management, Donghua University, \\ 201620 Shanghai, China
}

Received 08 March 2021; accepted 17 June 2021 ; first published online 14 December 2021

\begin{abstract}
Coworking spaces are becoming increasingly popular. Throughout literature, coworking spaces are commonly known as collaborative environments. Yet, there is a lack of research on the mechanisms of the collaborative practices within coworking spaces. This research identifies collaborative learning as a major collaborative practice within coworking spaces, and develops a conceptual framework including two other variables: individual motivation to learn and individual work performance. Exploratory factor analysis to establish the reliability and validity of this framework. Next, a survey study was conducted of 169 coworking space members and PLS-SEM was used to do a factor analysis and evaluate the structural model created. It is found that individual motivation to learn positively impacts collaborative learning, collaborative learning positively impacts individual work performance, and that collaborative learning acts as a full mediator between individual motivation to learn and individual work performance. These findings demonstrate how collaborative learning can be key in improving individual work performance in coworking spaces. Furthermore, these findings position collaborative learning as a theory that deserves further attention in coworking space research. These findings also suggest that coworking space operators may want to further encourage collaboration and incentivize learning in their space.
\end{abstract}

Keywords: coworking, coworking space, collaboration, collaborative learning, urban entrepreneurship, individual work performance.

JEL Classification: C3, D83, L26, O30.

\section{Introduction}

Coworking spaces are a relatively new phenomenon. The first modern coworking space was founded in 2005 in San Francisco by Brad Neuberg, as a communal working space. He coined this space a coworking space (Fost, 2008; Capdevila, 2013; Waters-Lynch et al., 2016). Since 2005, coworking has become increasingly popular. By the end of 2019, 2.2 million people were estimated to be members in over 22,000 coworking spaces worldwide (Foertsch, 2019). The popularity of coworking spaces can partially be explained by the cost-effective and

*Corresponding author. E-mails: koloswald@gmail.com; zxk@dhu.edu.cn

Copyright (C) 2022 The Author(s). Published by Vilnius Gediminas Technical University

This is an Open Access article distributed under the terms of the Creative Commons Attribution License (http://creativecommons. org/licenses/by/4.0/), which permits unrestricted use, distribution, and reproduction in any medium, provided the original author and source are credited. 
flexible nature of coworking. Renting a coworking space desk or office is usually relatively cheaper than renting a traditional office space, and comes with more contractual flexibility (Merkel, 2015). However, cost is not the only driving factor in explaining why coworking has become popular. Many coworking space operators believe collaboration to be of great importance in order to create an economic advantage (Orel \& Almeida, 2019). It is said that collaboration is deeply engrained coworking space culture (Blagoev et al., 2019). Yet, research of collaboration in this context is in its infancy stage and there is a clear need to develop the understanding here.

The relational aspect of coworking is a major reason for people to join coworking spaces (Parrino, 2015). Coworking spaces offer flexible business infrastructure and social areas that create a sense of community and social support (Gerdenitsch et al., 2016). Common social spaces within coworking spaces such as cafeterias, lounges and bars have been found to be key in fostering a collaborative community (Bouncken et al., 2020, 2021). A strong community seems to facilitate the successful operation of a coworking space (Rus \& Orel, 2015). It has been observed that coworking encourages cooperation among coworking space members (Waters-Lynch et al., 2016).

Collaboration and the co-creation of knowledge are often seen as central phenomena in coworking spaces (Capdevila, 2013; Goermar et al., 2021), with learning among coworking members being a common collaborative theme (Merkel, 2015). Thus, existing research suggests that collaboration is an important concept within coworking spaces, yet no structural relationship has been proven.

Bouncken and Reuschl (2018) created a theoretical framework in which learning within coworking spaces leads to positive performance outcomes. This study draws upon their framework, as their work is the first to illustrate the importance of the role of collaboration in creating positive performance outcomes. Whilst collaboration and learning have been discussed by several authors in the context of coworking spaces (Capdevila, 2013; WatersLynch et al., 2016; Orel \& Almeida, 2019), nobody has established a structural relationship between collaboration and positive performance outcomes. Since collaboration is a commonly discussed topic in this research area, establishing this relationship addresses an important research gap.

The purpose of this study is to evaluate the impact that collaborative learning has on individual work performance within coworking spaces, whilst also considering the individual motivation to learn. Dillenbourg (1999) states that collaborative learning occurs when two or more individuals come together to learn something, and this study seeks to establish collaborative learning as a core mechanism within the coworking context. Bouncken and Reuschl's (2018) framework was partially adopted and further developed. Three latent variables including two independent variables and one dependent variable were identified. This conceptual framework was then tested using exploratory factor analysis. After confirming validity and reliability, partial least squares structural equation modeling (PLS-SEM) was used in order to test the model. Lastly, the results and its implications were discussed.

This article is structured as follows. First, the theoretical background of the conceptual framework created is discussed. The theoretical relevance of each variable within the conceptual framework is identified, in order to show the relevance of the developed hypotheses. 
Next, the research methodology of both the pilot study and the final study are discussed, which is followed by the results and discussion section of this research enquiry. Lastly, the conclusions section offers a summary of this research, as well as limitations and future research opportunities.

\section{Theoretical background and hypothesis development}

Bouncken and Reuschl's (2018) framework was expanded upon, by creating the conceptual framework visible below (see Figure 1).

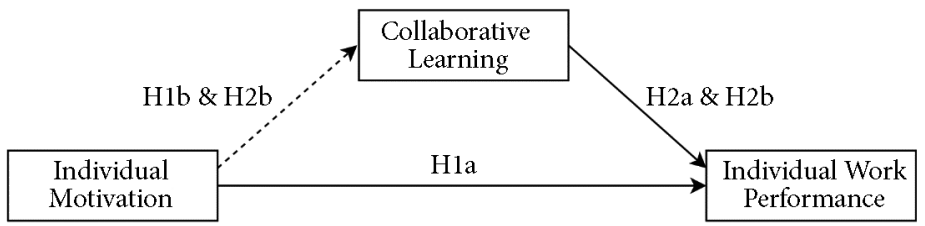

Figure 1. The conceptual framework

Firstly, learning was changed to collaborative learning. Bouncken and Reuschl (2018) describe learning in coworking spaces as occurring between individuals. It seems that this type of learning can be described as collaborative learning. Collaborative learning occurs when two or more individuals come together to learn something (Dillenbourg, 1999). The reason collaborative learning seems to be relevant within this context is because collaborative learning often happens in rich contexts, with the goal being to solve a particular problem (Smith \& MacGregor, 1992). This has been observed to be the case in coworking spaces, where members frequently work together and collaborate (Orel \& Almeida, 2019). This reciprocal type of learning has been observed on several occasions within coworking spaces (Bilandzic \& Foth, 2013; Goermar et al., 2021; Comunian \& Jacobi, 2020).

Secondly, the performance construct was developed further. Bouncken and Reuschl (2018) stated that an increase in performance caused by learning can be observed from an economic, entrepreneurial, economic, and job performance standpoint. In this model performance outcomes were defined as individual work performance outcomes. Existing empirically tested indicators were used for individual work performance (Koopmans et al., 2014).

Lastly, the concept of individual motivation was added, as individual motivation is found to be key when engaging in collaborative practices in coworking spaces (Capdevila, 2015; Clifton et al., 2019).

\subsection{Individual motivation to learn}

Both intrinsic and extrinsic motivators can be key in incentivizing individuals to learn in coworking spaces (Capdevila, 2015). Intrinsic motivators such as altruism, community commitment, social factors, and fun have been shown to be strong motivators for both collaboration and learning in hackerspaces, which are in many ways similar to coworking spaces (Moilanen, 2012). Nonetheless, motivation to learn in the context of collaborative learning is still not described fully and a lack of conceptual clarity exists (Jarvela et al., 2010). It is 
found that knowledge spillovers caused by collaborative learning can play a motivating role in itself to join a coworking space (Clifton et al., 2019).

It seems apparent that individual motivations to learn can differ. Bilandzic and Foth (2013) describe five personas that participate in social learning activities in coworking spaces, stating that these personas exhibit different types of motivation to learn. They conclude that it is necessary to motivate these five personas differently in order to maximize collaboration and social learning (Bilandzic \& Foth, 2013). It seems clear that individual motivation to learn is an important factor within this conceptual framework.

As such, it is theorized that individual motivation has a positive impact on collaborative learning and on individual work performance. Therefore, following hypotheses are proposed:

H1a. Individual motivation to learn has a positive impact on individual work performance of coworking space members.

H1b. Individual motivation to learn has a positive impact on collaborative learning.

\subsection{Collaborative learning}

Numerous coworking spaces around the world place an importance on collaboration (Orel \& Almeida, 2019), and the importance of this practice has been widely established (Bouncken et al., 2020; Capdevila, 2014; Kubatova, 2014). As such, coworking spaces themselves may have a duty to facilitate collaboration and create an exchange of ideas among coworking space members (Kubatova, 2014).

Coworking spaces enable collaborative practices by several means. Firstly, coworking spaces are designed to break rigid organizational structures that inhibit individuals from collaborating (Bouncken et al., 2020). As the organizational structure of a coworking space encourages individuals from different organizations to interact, collaboration among individuals is fostered (Spinuzzi et al., 2019). Secondly, this type of environment may act as psychological empowerment to coworking space members, and encourage them to engage in creative activities (Bouncken et al., 2020). Lastly, coworking spaces often organize social events which further encourage individuals to collaborate with each other (Capdevila, 2014). Yet, as collaborative practices are mostly voluntary, space members may decide not to partake in community activities, working individually instead (Bouncken et al., 2020). As coworking spaces exhibit different types of structures, different types of communities and collaborative settings exist (Capdevila, 2014).

Capdevila (2014) found that there are also different types of collaboration occurring in coworking spaces. These types can be described as cost-related, resource-based, and relational. Capdevila (2014) finds that learning occurs in resource-based and relational collaboration environments. Bilandzic (2013) confirms that collaborative learning is present in coworking spaces by finding that members commonly participate in social learning experiences. Whilst collaborative learning has a low prescriptiveness in activity, it can apply to a wide range of learning activities. Of the defining characteristics of collaborative learning is that it draws upon social relationships and that learning occurs within a community (Oxford, 1997).

Dillenbourg (1999) further elaborates on the process of collaborative learning by stating that two or more individuals must be involved in a learning process. He also states that this 
process can involve formal education, but can also happen in the form of informal problem solving as long as a social aspect exists.

Thus, since learning in coworking is found to include collaboration and occur in social settings (Butcher, 2018; Merkel, 2017), it is hypothesized that:

$\mathrm{H} 2 \mathrm{a}$. Collaborative learning has a positive impact on individual work performance of coworking space members.

Furthermore, it is also hypothesized that collaborative learning acts as a mediator between individual motivation to learn and individual work performance. This is because individual motivation may be needed to engage in collaborative learning, but without collaborative learning there may be a lack of improvement in individual work performance. As such, the hypothesis is as follows:

$\mathrm{H} 2 \mathrm{~b}$. Collaborative learning has a positive impact as a mediator between individual motivation and individual work performance of coworking space members.

\subsection{Individual work performance}

Bouncken and Reuschl (2018) theorized that coworking can improve individual work performance, whilst it has also been found that coworking can affect entrepreneurial performance (Bouncken et al., 2020). More specifically, the support and interaction with coworkers seems to positively affect individual work performance (Singh et al., 2019). As such, this study seeks to show that both the individual motivation to learn and collaborative learning within coworking spaces have a positive impact on individual work performance. Showing these structural relationships would be a contribution to current knowledge, because they would offer an explanation as to how coworking improves individual work performance.

It has been previously shown that various types of learning can improve work performance (Billet, 2001). Learning can improve the performance of an individual for the benefit of the organization, for the benefit of the individual, or seen as a social investment (Boud et al., 2000). Furthermore, learning at work has shown to influence both technical and interpersonal aspects of job performance (Reio \& Wiswell, 2000). It has also been found that supervisors can increase informal learning in work teams, by facilitating the learning process (Macneil, 2001). Hence, assessing the structural relationships shown in Figure 1, will contribute towards the understanding of the relationships between these three variables in the context of coworking.

\section{Methodology}

A set of hypotheses were formulated according to the existing theory, that were then tested using partial least squares structural equation modeling (PLS-SEM). PLS-SEM is often used to develop theories in exploratory research, and is considered to be more favorable at the theory development stage than covariance based structural equation modeling (Hair et al., 2016). It is a non-parametric component-based estimation approach that maximizes the amount of variance explained, whilst converging in relatively few iterations. Thus, one advantage of using PLS-SEM is that it works well with relatively small sample sizes (Astrachan 
et al., 2014). In PLS-SEM the explained variance of the dependent latent variable is maximized. As this is different to covariance-based SEM, PLS-SEM requires different testing criteria (Hair et al., 2016). Furthermore, PLS-SEM emphasizes providing causal explanations (Sarstedt et al., 2014). Lastly, PLS-SEM has been found to provide a better model fit whilst also showing less contradictive results in the context of mediator relationships as compared to regression analysis (Ramli et al., 2018).

Two data samples were used. First, a pilot study was conducted with a sample of 67 respondents. This was done to test the reliability and validity of the instrument scales. Second, a new sample of 182 respondents was collected to conduct the PLS-SEM. Study participants of both samples fully consented in partaking in the survey and were assured that the data was solely used for academic purposes. All survey data was collected anonymously in order to ensure ethical conduct.

\subsection{Measurement}

The conceptual framework created includes two independent variables and one dependent variable. The two independent variables are collaborative learning (CL) and individual motivation to learn (IM). The dependent variable is Individual Work Performance (IWP). For each of these variables four indicators were initially selected. As there were no existing empirically tested indicators for CL and IM, four indicators were created using existing theoretical knowledge, that corresponded with the construct being measured. For the dependent variable IWP four empirically tested indicators were used (Koopmans et al., 2014). As parts of the model were untested, it was deemed necessary to conduct a pilot study in order to establish research validity and reliability.

\subsection{Pilot study}

In order to establish validity and reliability of the conceptual framework, a pilot study with a sample size of 67 was done. This sample was then used to run an exploratory factor analysis using SPSS 26. The pilot study survey was sent out to coworking space members using the social media application WeChat and convenience sampling was used. All of this data was collected in March 2020. Furthermore, five respondents of the survey were asked for insights on improving the survey.

The pilot study established the reliability of the constructs. All of the tested constructs are visible in Table 1, and the exploratory factor analysis done resulted he exploratory in reducing the total number of indicators from 12 to 10. The two indicators IM2 and IWP2 were removed due to poor factor loading. IM2 had a factor loading of 0.639 on factor 2 , it also had a cross-loading of 0.346 on factor 1 . IWP2 had a factor loading of 0.488 on factor 3 , and a cross-loading of 0.400 on factor 1 . Hence, both IM2 and IWP2 were removed to improve model fit. Table 2 shows the factor loadings of the 10 remaining indicators. As is visible, all individual factor loadings were significantly above 0.5 , which is considered practically significant (Hair et al., 2019). The three latent variables CL, IM, and IWP, had average loadings of $0.837,0.818$, and 0.775 respectively. This showed a well-defined structure of the model (Hair et al., 2019). Thus, convergent validity was established. 
Table 1. Constructs and measurement questions

\begin{tabular}{|l|l|}
\hline Construct & \\
\hline CL1 & Members at this co-working space often teach each other skills. \\
\hline CL2 & Members at this co-working space work together on tasks. \\
\hline CL3 & Members commonly give each other feedback on work-related tasks. \\
\hline CL4 & When a member needs help for a task, the community will help him. \\
\hline IM1 & I am interested in learning new skills. \\
\hline IM2 & I am interested in learning from others. \\
\hline IM3 & I am happy to teach skills to other members at this coworking space. \\
\hline IM4 & I am eager to work together with other members at this coworking space. \\
\hline IWP1 & As a result of being at the co-working space my work quality has increased. \\
\hline IWP2 & As a result of being at the coworking space my job knowledge has increased. \\
\hline IWP3 & Being a member of the co-working space has helped me increase my job skills. \\
\hline IWP4 & Being a member of the co-working space has increased my work efficiency. \\
\hline
\end{tabular}

Table 2. Factor loadings

\begin{tabular}{|l|c|c|c|}
\hline \multicolumn{1}{|c|}{ Construct } & Factor 1 & Factor 2 & Factor 3 \\
\hline CL4 & 0.913 & 0.087 & -0.268 \\
\hline CL1 & 0.860 & -0.093 & 0.067 \\
\hline CL3 & 0.794 & 0.035 & 0.073 \\
\hline CL2 & 0.780 & -0.040 & 0.141 \\
\hline CL Average & 0.837 & & -0.028 \\
\hline IM3 & 0.091 & 0.875 & 0.121 \\
\hline IM1 & -0.183 & 0.799 & -0.068 \\
\hline IM4 & 0.096 & 0.781 & 0.875 \\
\hline IM Average & & 0.818 & 0.832 \\
\hline IWP1 & 0.075 & -0.135 & 0.619 \\
\hline IWP4 & -0.199 & 0.110 & 0.775 \\
\hline IWP3 & 0.293 & 0.125 & 0.614 \\
\hline IWP Average & & & 0.671 \\
\hline Average Variance Extracted & 0.703 & & \\
\hline
\end{tabular}

Discriminant validity was also established as there were no significant cross loadings and the component correlation matrix showed a maximum value of 0.448 . Total variance explained amounted to 0.71 , which was above the acceptable threshold of 0.6 (Hair et al., 2013). The Kaiser-Meyer-Olkin value was 0.742 , which was also adequate (Kaiser, 1974). 
Bartlett's test of sphericity showed a significant level of 0.000 , showing significant correlation among the indicators in the EFA (Tobias \& Carlson, 1969). Lastly, the lowest communality extracted was 0.617 , which was also sufficient (Costello \& Osborne, 2005). Thus, adequacy of the data was established.

The reliability of the pre-test was established as the Cronbach Alpha values of the three factors were 0.862 (CL), 0.715 (IM), and 0.749 (IWP), which was higher than the recommended value of 0.7 (Lance et al., 2006). Thus, the exploratory factor analysis of the pre-test showed both the reliability and validity of the construct measured.

\subsection{Survey design and data collection}

The survey included two parts. The first part of the survey included ten questions that were each designed to measure a single indicator of the three latent variables. For this a 5-point Likert scale was used, and the scale was organized as follows: (1) strongly disagree, (2) disagree, (3) neither agree nor disagree, (4) agree, and (5) strongly agree. The second part of the survey asked four basic demographic questions about duration of membership at the coworking space, the name of the coworking space respondents were members of, the highest level of education of the respondents, as well as the respondent's age. The question about the name of the coworking space was the only open question in the survey, and it was included for data screening purposes. If respondents omitted this question, their data was not used.

In total 182 surveys were collected using convenience sampling. 50 coworking space owners were contacted to share our surveys, of which 11 owners agreed to share the survey. The 11 owners operated coworking spaces in five different countries. These owners were approached via WeChat and LinkedIn and were asked to kindly disperse the surveys among their coworking space members. Additionally, the survey was shared with online coworking communities on WeChat and LinkedIn. Members of these communities were encouraged to share the survey with other coworking space members. Each respondent of the survey was encouraged to share the survey further. This snowball sampling technique resulted in receiving responses from coworking space members from 56 different coworking spaces in 19 different countries.

Once these 182 surveys were collected, data screening was conducted. As the target population of this research was coworking space members, the most important factor was that respondents were actually active coworking space members. As such, one of the data screening questions was designed to filter out inactive users. 4 surveys were removed where respondents failed to provide a coworking space name. 9 surveys were removed due to invariant responding. Invariant responding occurs when the respondent selects the same option repeatedly, indicating a lack of effort (DeSimone et al., 2015). Finally, a total of 169 surveys with respondents from 56 different coworking spaces was used for this research enquiry.

The minimum sample size in a PLS-SEM model is often argued to be at least 10 times the maximum number of arrowheads pointing towards a latent variable (Hair et al., 2016). In order to get a more accurate indication of the required minimum sample size, a $\mathrm{G}^{\star}$ Power test was used (Erdfelder et al., 1996). This test showed a minimum sample size of 89 . Hence, the sample of 169 was considered large enough. 


\section{Results}

\subsection{Sample demographics}

Table 3 shows the basic demographic breakdown. Only 1.2\% of respondents were members of their coworking space for less than six months. This shows that most respondents had been members for a considerable amount of time. The overall education level of this sample was relatively high, with over half of the respondents possessing a postgraduate degree. Lastly, more than half of the respondents in this sample were within the age range of 28 to 37 . This may either be due to the sampling technique used, or it may indicate a general demographic trend among coworking space users.

Table 3. Demographic breakdown of survey respondents

\begin{tabular}{|l|l|c|c|}
\hline \multicolumn{1}{|c|}{ Category } & \multicolumn{1}{|c|}{ Subcategory } & Frequency & Percent (\%) \\
\hline \multirow{4}{*}{$\begin{array}{l}\text { Duration of } \\
\text { membership }\end{array}$} & Less than 6 months & 2 & 1.2 \\
\cline { 2 - 4 } & 6 Months to a year & 74 & 43.8 \\
\cline { 2 - 4 } & 1 To 2 years & 56 & 33.1 \\
\cline { 2 - 4 } & More than 2 years & 37 & 21.9 \\
\hline \multirow{4}{*}{ Education } & No university degree & 71 & 4.7 \\
\cline { 2 - 4 } & Bachelors or Associates degree & 90 & 42.0 \\
\cline { 2 - 4 } & Master's degree or higher & 41 & 53.3 \\
\hline \multirow{5}{*}{ Age } & $18-27$ & 86 & 24.2 \\
\cline { 2 - 4 } & $28-37$ & 28 & 50.9 \\
\cline { 2 - 4 } & $38-47$ & 11 & 16.6 \\
\cline { 2 - 4 } & $48-57$ & 3 & 6.5 \\
\cline { 2 - 4 } & $58+$ & & 1.8 \\
\hline
\end{tabular}

\subsection{Factor analysis}

As is visible in Table 4, all Cronbach's alpha (CA) values were above 0.7, with the lowest value being 0.752 (IM). Additionally, composite reliability (CR) ranged from 0.749 to 0.839 , with all values significantly above the 0.6 value threshold (Hair et al., 2016). Thus, internal consistency reliability was achieved.

Table 4 shows that all average variance explained (AVE) values were above 0.5 . This shows that the model explains more than half of the variance of its indicators (Hair et al., 2016). All outer loadings were significantly higher than 0.5 , which is considered the cutoff value for an outer loading in PLS (Hulland, 1999). The lowest outer loading within this model was 0.613 (IM1). Also, all latent variables had average outer loadings higher than 0.7 , ranging from 0.704 (IM) to 0.751 (CL), further confirming convergent validity.

In order to assess discriminant validity in PLS-SEM, the heterotrait-monotrait ratio of correlations (HTMT) was used as well as the Fornell-Larcker Criterion. The HTMT is an alternative approach to the Fornell and Larcker Criterion, that has shown superior results in assessing discriminant validity compared to the Fornell and Larcker Criterion (Henseler 
et al., 2015). As is visible in Table 5, the HTMT values for the three latent variables ranged from 0.362 to 0.689 . As all values were less than 1, the HTMT test established discriminant validity (Henseler et al., 2015).

Table 4. Reliability and convergent validity

\begin{tabular}{|c|c|c|c|c|c|c|}
\hline Construct & Items & $\begin{array}{c}\text { Outer } \\
\text { Loadings }\end{array}$ & $\begin{array}{l}\text { Average Outer } \\
\text { Loading }\end{array}$ & CA & AVE & CR \\
\hline \multirow{4}{*}{$\begin{array}{l}\text { Collaborative } \\
\text { Learning }\end{array}$} & CL1 & 0.817 & \multirow{4}{*}{0.751} & \multirow{4}{*}{0.835} & \multirow{4}{*}{0.566} & \multirow{4}{*}{0.839} \\
\hline & CL2 & 0.765 & & & & \\
\hline & CL3 & 0.728 & & & & \\
\hline & CL4 & 0.694 & & & & \\
\hline \multirow{3}{*}{$\begin{array}{l}\text { Individual } \\
\text { Motivation }\end{array}$} & IM1 & 0.613 & \multirow{3}{*}{0.704} & \multirow{3}{*}{0.752} & \multirow{3}{*}{0.502} & \multirow{3}{*}{0.749} \\
\hline & IM3 & 0.695 & & & & \\
\hline & IM4 & 0.804 & & & & \\
\hline \multirow{3}{*}{$\begin{array}{l}\text { Individual } \\
\text { Work } \\
\text { Performance }\end{array}$} & IWP1 & 0.725 & \multirow{3}{*}{0.742} & \multirow{3}{*}{0.793} & \multirow{3}{*}{0.559} & \multirow{3}{*}{0.789} \\
\hline & IWP3 & 0.858 & & & & \\
\hline & IWP4 & 0.644 & & & & \\
\hline
\end{tabular}

Table 5. The Heterotrait-Monotrait (HTMT) ratio of correlations

\begin{tabular}{|l|c|c|c|}
\hline \multicolumn{1}{|c|}{ Construct } & CL & IWP & IM \\
\hline Collaborative Learning (CL) & & & \\
\hline Individual Work Performance (IWP) & 0.510 & & \\
\hline Individual Motivation (IM) & 0.689 & 0.362 & \\
\hline
\end{tabular}

Furthermore, the Fornell-Larcker Criterion was also met as seen in Table 6. All the square root values of AVE were greater (seen in bold) than any other correlations between constructs (the non-diagonal values) (Fornell \& Larcker, 1981).

Table 6. Fornell-Larcker criterion

\begin{tabular}{|l|c|c|c|}
\hline \multicolumn{1}{|c|}{ Construct } & CL & IWP & IM \\
\hline Collaborative Learning (CL) & 0.752 & & \\
\hline Individual Work Performance (IWP) & 0.507 & 0.708 & \\
\hline Individual Motivation (IM) & 0.687 & 0.381 & 0.748 \\
\hline
\end{tabular}

\subsection{Structural model}

In PLS-SEM collinearity is assessed before hypothesis testing (Hair et al., 2016). In order to assess collinearity, the Variation Inflation Factors (VIF) were used to assess outer and inner values. The ten outer VIF values ranged from 1.468 to 2.527 , whereas the three inner VIF values ranged from 1.000 to 1.346 . Collinearity was not an issue as all values were significantly below 5 . Table 7 shows that of the four hypotheses, hypothesis $1 \mathrm{~b}, 2 \mathrm{a}$, and $2 \mathrm{~b}$ 
were supported, whilst hypothesis 1a was not supported. Figure 2 shows the final structural equation model (see Figure 2).

Table 7. Results of hypothesis testing

\begin{tabular}{|c|l|c|c|c|c|}
\hline Hypothesis & \multicolumn{1}{|c|}{ Path } & Path Coefficient & T Statistics & p-Value & Supported \\
\hline 1a & IM -> IWP & 0.045 & 0.385 & 0.700 & No \\
\hline lb & IM -> CL & 0.506 & 4.857 & $0.000^{*}$ & Yes \\
\hline 2a & CL -> IWP & 0.669 & 6.197 & $0.000^{*}$ & Yes \\
\hline 2b & IM -> CL -> IWP & 0.341 & 3.386 & 0.001 & Yes \\
\hline
\end{tabular}

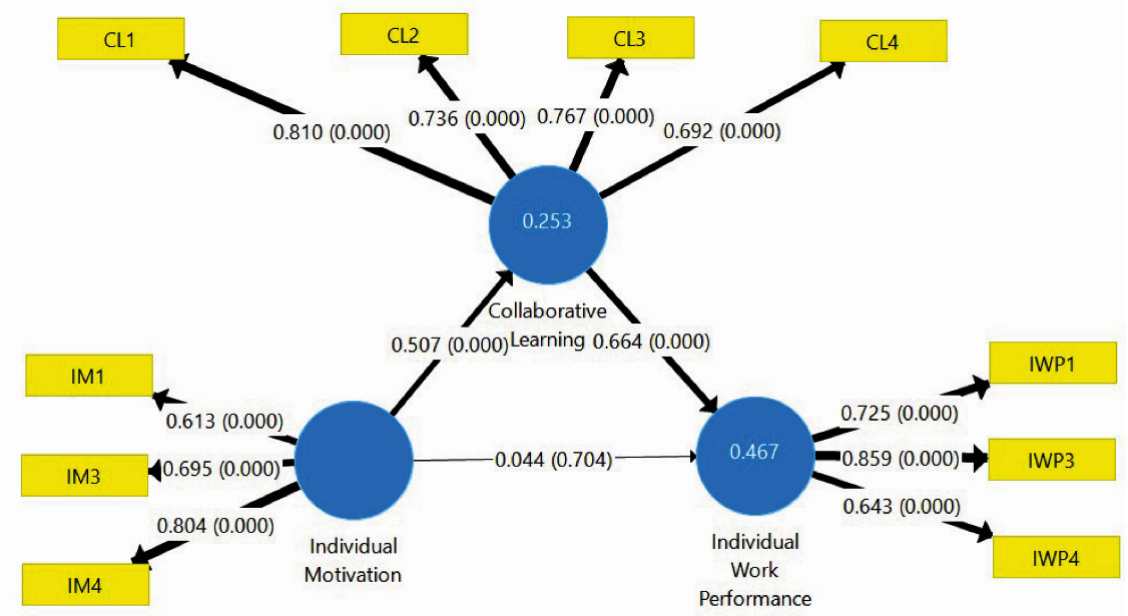

Figure 2. The final structural equation model

Individual motivation did not have a direct positive impact on individual work performance, as the direct path coefficient was only 0.041 . The p-Value of this relationship was 0.7 and Hypothesis la was therefore not supported. Whilst this was not hypothesized to be the case, taking the total effect that individual motivation has on individual work performance into account, offers insight into why this hypothesis was not supported. The total effect between individual motivation and individual work performance was significant, as the path coefficient was 0.386 with a p-value of 0.000 . Thus, whilst Hypothesis la was not supported, a significant total effect did exist.

Individual motivation is shown to have a direct positive effect on collaborative learning, with a path coefficient of 0.506 and a p-Value of 0.000 . Hypothesis $1 \mathrm{~b}$ was therefore supported. This confirmed the hypothesis that individuals with higher motivations to learn engage in more collaborative learning. Thus, individual motivation is an important construct within this model, as it can give insight into varying levels of collaborative learning.

Collaborative learning had a direct positive effect on individual work performance. The path coefficient of 0.669 showed a particularly strong positive effect. As the p-Value was 0.000 , Hypothesis $2 \mathrm{a}$ was supported. This confirms the importance that collaborative learning has in creating positive individual work performance outcomes. As such, this relationship may explain a unique advantage that coworking spaces have over traditional office spaces. 
Lastly, Hypothesis $2 \mathrm{~b}$ was also confirmed. The path coefficient of this relationship was 0.346 , with a p-Value of 0.001 . As this study assumes a confidence level of $5 \%$, any p-Value smaller than 0.005 was acceptable. This showed that collaborative learning acts as a mediator in a positive relationship between individual motivation and individual work performance.

As Hypothesis 1a was insignificant, and both hypothesis $1 \mathrm{~b}$ and $2 \mathrm{a}$ were significant, this is a case of full mediation. Full mediation explains why Hypothesis 1a was not supported, and sheds insight on how individual motivation still had a strong total effect on individual work performance.

The tested models $\mathrm{R} 2$ value was 0.473 , and its adjusted $\mathrm{R}^{2}$ value was 0.467 . This value can be considered moderate, as Chin (1998) stated that $\mathrm{R}^{2}$ values of $0.67,0.33$, and 0.19 in PLS models can be seen as substantial, moderate, and weak (Chin, 1998). Other authors agree with this assessment of a moderate $\mathrm{R}^{2}$, whilst limiting it to the context of simple models with one or two exogenous latent variables (Henseler et al., 2009). As this study was limited to two exogenous variables, this further confirms that the $\mathrm{R}^{2}$ value here can be considered as moderate.

Furthermore, $\mathrm{f}^{2}$ values were analyzed and are depicted in Table 8 . These $\mathrm{f}^{2}$ values show how much an exogenous variable contributes to an endogenous variables R2 value (Wong, 2013). According to Cohen (1988) a direct effect between two variables can be considered large when it has a value of 0.35 . Thus, the effect of CL on IWP can certainly be considered as large as the $\mathrm{f}^{2}$ value reported was 0.623 . Furthermore, the effect of IM on CL can also be considered as large as its $\mathrm{f}^{2}$ value was 0.346 , which is marginally below 0.35 .

Table 8. $\mathrm{f}^{2}$ values

\begin{tabular}{|l|c|c|c|}
\hline \multicolumn{1}{|c|}{ Construct } & CL & IM & IWP \\
\hline Collaborative Learning (CL) & & & 0.623 \\
\hline Individual Motivation (IM) & 0.346 & & 0.003 \\
\hline Individual Work Performance (IWP) & & & \\
\hline
\end{tabular}

Also, the $\mathrm{Q}^{2}$ value of the dependent variable was measured in order to assess the constructs predictive relevance (Hair et al., 2012). This was done by running a Blindfolding test in Smart PLS using an omission distance of 7. This is the commonly used omission distance, with the recommended distance being 5 to 10 (Hair et al., 2016). The $\mathrm{Q}^{2}$ value of IWP was found to be 0.217 , which suggests that this model has a medium predictive relevance, as a value of over 0.15 suggests moderate predictive relevance (Henseler et al., 2009).

Standardized root mean squared residual (SRMR) was used to measure model fit (Sarstedt et al., 2014). The cutoff value for the SRMR is 0.08 (Hu \& Bentler, 1999), and in order for a model to show model fit the models SRMR value should be under 0.08 . In this case, the SRMR value equated to 0.04 , confirming the model fit.

\section{Discussion}

As both collaboration and learning are heavily discussed within coworking space literature, collaborative learning was found to be a key construct relevant to the context of coworking space. Placing this variable within the created framework was the first major contribution. 
Collaborative learning was found to have a strong impact on individual work performance. This is a key finding of our study as it illustrates the importance of collaborative practices within coworking spaces. There has been much discussion on the importance of collaboration in coworking, and this is the first study to show a measurable benefit of this variable. We thereby contribute to the theoretical literature by showing a structural relationship and a positive relationship between collaborative learning and individual work performance.

Also, the positive impact that individual motivation to learn shows the importance of motivation from an individual perspective. As Capdevila (2014) showed different types of collaborative environments within coworking spaces, this result shows that it is also important to look at collaboration on an individual level. Setting the right incentive structures and creating a collaborative culture may help attract individuals that are motivated to participate in collaborative learning activities.

Whilst we found that individual motivation does not significantly impact individual work performance directly, it still has a significant total effect relationship, as collaborative learning acts as a full mediator. This explains why our Hypothesis 1a was shown to be insignificant, and gives further insight into the importance of all three latent variables within our model.

This study thereby shows the relationships between the three factors, and gives insight into how collaborative learning can improve individual work performance in coworking spaces. Individual motivation acts as an important catalyst here, and the model offers explanation as to how motivated individuals engage in higher levels of collaborative learning. Consequently, higher levels of collaborative learning will result in increased individual work performance. These positive performance outcomes are desirable for both individuals and coworking spaces, and therefore underline our contribution.

These findings contribute towards coworking space literature, as they progress the theoretical understanding of collaboration and learning in coworking spaces. All in all, this study places collaborative learning as a key construct within coworking spaces. Collaboration and community are often inaccurately described when it comes to coworking spaces, and as such a fragmented discussion is necessary (Spinuzzi et al., 2019). The degree to which collaborative learning occurs in a coworking space certainly depends on the context. As coworking spaces exhibit varying degrees of collaborative practices, collaborative learning will also vary, as there may be a lack of community to facilitate it. There is therefore a strong need for a nuanced approach to research on collaborative practices within coworking spaces, as they are clearly context dependent.

\subsection{Managerial implications}

As this study confirms the merit of collaborative learning, coworking spaces should consider creating incentives for collaborative behavior. Not every coworking space may wish to encourage collaboration, but if they do, they should design their offices in a way that encourages idea exchange. By creating an open office environment, coworking members may be more inclined to communicate with each other. Additionally, coworking space operators should try and create communal areas, such as a communal cafeteria, lounge area, or bar. Any type of communal space increases the opportunities for coworking space members to socialize. Additionally, the coworking space should organize social events in order to strengthen social ties 
among members. There may be many other ways to encourage collaboration among members in coworking and this paper shows the need for managerial teams to make this a priority.

As this paper establishes individual motivation to learn as a key factor in collaborative learning behavior, this has major implications for coworking spaces. Coworking space managers should consider how they can create more individual incentives for members to engage in collaborative learning. Additionally, they may want to become selective in the members they accept to the space, in order to create a culture of motivated individuals. It would be favorable for coworking spaces to encourage learning. This can be done in various ways such as creating formal workshops that can be organized and taught by members as well, or gamifying learning by competitions such as hackathons. All in all, managers at coworking spaces should attempt to encourage individuals to engage in collaborative learning, while also creating a coworking space environment that fosters collaborative learning.

\section{Conclusions}

This study examined the relationships between individual motivation to learn, collaborative learning, and individual work performance, within the context of coworking spaces. We found that individual motivation to learn positively impacts collaborative learning, and that collaborative learning positively impacts individual work performance. Whilst individual motivation does not significantly impact individual work performance directly, it does have an indirect effect on it. Collaborative learning acts as a full mediator in the relationship between individual motivation and individual work performance. Therefore, only hypothesis 1a was not supported, whilst hypotheses $1 \mathrm{~b}, 2 \mathrm{a}$, and $2 \mathrm{~b}$ were all supported.

These findings contribute to the theory of coworking spaces, by being the first to structurally show how a collaborative practice can cause positive outcomes. There have been various findings theorizing that collaboration is of importance in coworking spaces, and this study shows how collaborative learning positively impacts individual work performance. Additionally, this study places individual motivation to learn as an important variable in the coworking context. Firstly, individual motivation has a positive impact on collaborative learning. Secondly, collaborative learning acts as a full mediator between individual motivation to learn and individual work performance. There is a need for future research to place an emphasis on motivation at an individual level within this context.

In conclusion, this study contributes to the understanding of collaboration within coworking spaces, and positions collaborative learning as a key collaborative practice.

This study had several limitations. First of all, all data was gathered via social media channels. As all data was obtained electronically, it cannot be completely verified. Even though the data was screened thoroughly, it was impossible to completely verify each identity. Also, as we used social media channels, the data sample may exhibit some degree of user bias. Thus, further research could adopt a more diverse data gathering strategy. Secondly, not all of the indicator variables had previously been empirically tested. Therefore, it was necessary to create our own indicators. These were empirically tested using exploratory factor analysis, yet in the future, further confirmatory analysis would be appropriate. Lastly, as five-point Likert scale questions were used, there was a certain limit to portraying the feelings of respondents. As such, in future research on this topic, a more accommodating question style may offer additional insights. 
As the structural model was established successfully, future research can expand upon this. This structural model could be expanded upon and tested with various other constructs. Additionally, future coworking space research may develop collaborative learning research further, in order to create a more holistic understanding of coworking spaces as a whole.

Furthermore, individual motivation to learn and individual work performance are both factors that offer further research opportunities. For instance, individual motivation could be split up into intrinsic and extrinsic motivators, in order to examine how different types of motivation shape collaborative learning within coworking spaces. As Bouncken's and Reuschl's model (2018) did not specify performance, future research can also expand upon individual work performance, by testing other performance outcomes.

Also, future studies may concentrate on demographic factors in relationship to the variables. It may perhaps be particularly interesting to investigate the relationship between the education background of coworking space members individually and as a community and the impact this has on collaborative learning.

Lastly, as collaborative learning is at the core of this research, we deem this construct as a promising research stream. Future research could investigate collaborative learning in a bigger picture, or examine it in regards to other collaborative practices.

\section{Acknowledgements}

The authors thank the reviewers of the journal for their helpful comments.

\section{Author contributions}

$\mathrm{KO}$ and $\mathrm{XZ}$ conceptualized the study and were responsible for the design and development. $\mathrm{KO}$ was responsible for data collection, analysis, and interpretation. $\mathrm{KO}$ was responsible for writing the draft. XZ supervised and edited the draft.

\section{Disclosure statement}

The authors declare no conflict of interest.

\section{References}

Astrachan, C. B., Patel, V. K., \& Wanzenried, G. (2014). A comparative study of CB-SEM and PLS-SEM for theory development in family firm research. Journal of Family Business Strategy, 5(1), 116-128. https://doi.org/10.1016/j.jfbs.2013.12.002

Bilandzic, M. V. (2013). The embodied hybrid space: Designing social and digital interventions to facilitate connected learning in coworking spaces. Queensland University of Technology. https://core.ac.uk/download/pdf/16749371.pdf

Bilandzic, M., \& Foth, M. (2013). Libraries as coworking spaces: Understanding user motivations and perceived barriers to social learning. Library Hi Tech, 31(2), 254-273. https://doi.org/10.1108/07378831311329040

Billett, S. (2001). Learning in the workplace: Strategies for effective practice. ERIC. https://eric.ed.gov/?id=ED465870 
Blagoev, B., Costas, J., \& Kärreman, D. (2019). "We are all herd animals": Community and organizationality in coworking spaces. Organization, 26(6), 894-916. https://doi.org/10.1177/1350508418821008

Boud, D., Garrick, J., \& Greenfield, K. (2000). Understanding learning at work. Performance Improvement, 39(10), 45-47. https://doi.org/10.1002/pfi.4140391013

Bouncken, R. B., Aslam, M. M., \& Qiu, Y. (2021). Coworking spaces: Understanding, using, and managing sociomateriality. Business Horizons, 64(1), 119-130. https://doi.org/10.1016/j.bushor.2020.09.010

Bouncken, R., Ratzmann, M., Barwinski, R., \& Kraus, S. (2020). Coworking spaces: Empowerment for entrepreneurship and innovation in the digital and sharing economy. Journal of Business Research, 114, 102-110. https://doi.org/10.1016/j.jbusres.2020.03.033

Bouncken, R. B., \& Reuschl, A. J. (2018). Coworking-spaces: How a phenomenon of the sharing economy builds a novel trend for the workplace and for entrepreneurship. Review of Managerial Science, 12(1), 317-334. https://doi.org/10.1007/s11846-016-0215-y

Butcher, T. (2018). Learning everyday entrepreneurial practices through coworking. Management Learning, 49(3), 327-345. https://doi.org/10.1177/1350507618757088

Capdevila, I. (2013). Knowledge dynamics in localized communities: Coworking spaces as microclusters. SSRN. https://doi.org/10.2139/ssrn.2414121

Capdevila, I. (2014). Different inter-organizational collaboration approaches in coworking spaces in Barcelona. SSRN. https://doi.org/10.2139/ssrn.2502816

Capdevila, I. (2015). Co-working spaces and the localised dynamics of innovation in Barcelona. International Journal of Innovation Management, 19(3), 1540004. https://doi.org/10.2139/ssrn.2502813

Chin, W. W. (1998). The partial least squares approach to structural equation modeling. In G. A. Marcoulides (Ed.), Modern methods for business research (pp. 295-336). Lawrence Erlbaum Associates Publishers.

Clifton, N., Füzi, A., \& Loudon, G. (2019). Coworking in the digital economy: Context, motivations, and outcomes. Futures, 102439. https://doi.org/10.1016/j.futures.2019.102439

Cohen, J. (1988). Statistical power analysis for the behavioral sciences ( $2^{\text {nd }}$ ed.). Lawrence Erlbaum Associates.

Comunian, R., \& Jacobi, S. (2020). Growing collaborative creative learning spaces: The case of London School of Mosaic. In Collaborative spaces at work (pp. 268-281). Routledge. https://taylorfrancis. com/chapters/edit/10.4324/9780429329425-20/growing-collaborative-creative-learning-spacesroberta-comunian-silvie-jacobi

Costello, A. B., \& Osborne, J. (2005). Best practices in exploratory factor analysis: Four recommendations for getting the most from your analysis. Practical Assessment, Research, and Evaluation, 10(1), 7. https://scholarworks.umass.edu/pare/vol10/iss1/7/

DeSimone, J. A., Harms, P. D., \& DeSimone, A. J. (2015). Best practice recommendations for data screening. Journal of Organizational Behavior, 36(2), 171-181. https://doi.org/10.1002/job.1962

Dillenbourg, P. (1999). What do you mean by collaborative learning? In Collaborative learning: Cognitive and computational approaches (pp. 1-19). Elsevier. https://telearn.archives-ouvertes.fr/hal-00190240/document

Erdfelder, E., Faul, F., \& Buchner, A. (1996). GPOWER: A general power analysis program. Behavior Research Methods, Instruments, \& Computers, 28(1), 1-11. https://doi.org/10.3758/BF03203630

Foertsch, C. (2019). 2019 state of coworking: Over 2 million coworking space members expected. DESKMAG. http://www.deskmag.com/en/2019-state-of-coworking-spaces-2-million-members-growthcrisis-market-report-survey-study

Fornell, C., \& Larcker, D. F. (1981). Structural equation models with unobservable variables and measurement error: Algebra and statistics. Journal of Marketing Research, 18(3), 382-388.

https://doi.org/10.2307/3150980 
Fost, D. (2008, February 21). Coworking: A cooperative for the modern age. The New York Times. https://www.nytimes.com/2008/02/21/technology/21iht-cowork.1.10263648.html

Gerdenitsch, C., Scheel, T. E., Andorfer, J., \& Korunka, C. (2016). Coworking spaces: A source of social support for independent professionals. Frontiers in Psychology, 7, 581.

https://doi.org/10.3389/fpsyg.2016.00581

Goermar, L., Barwinski, R. W., Bouncken, R. B., \& Laudien, S. M. (2021). Co-Creation in coworkingspaces: Boundary conditions of diversity. Knowledge Management Research \& Practice, 19(1), 53-64. https://doi.org/10.1080/14778238.2020.1740627

Hair, J. F., Ringle, C. M., \& Sarstedt, M. (2013). Partial least squares structural equation modeling: Rigorous applications, better results and higher acceptance. Long Range Planning, 46(1-2), 1-12. https://ssrn.com/abstract $=2233795$

Hair, J. F., Risher, J. J., Sarstedt, M., \& Ringle, C. M. (2019). When to use and how to report the results of PLS-SEM. European Business Review, 31(1), 2-24. https://doi.org/10.1108/EBR-11-2018-0203

Hair, J. F., Sarstedt, M., Ringle, C. M., \& Mena, J. A. (2012). An assessment of the use of partial least squares structural equation modeling in marketing research. Journal of the Academy of Marketing Science, 40(3), 414-433. https://doi.org/10.1007/s11747-011-0261-6

Hair, Jr, J. F., Hult, G. T. M., Ringle, C., \& Sarstedt, M. (2016). A primer on partial least squares structural equation modeling (PLS-SEM) ( $2^{\text {nd }}$ ed.). Sage Publications.

Henseler, J., Ringle, C. M., \& Sarstedt, M. (2015). A new criterion for assessing discriminant validity in variance-based structural equation modeling. Journal of the Academy of Marketing Science, 43(1), 115-135. https://doi.org/10.1007/s11747-014-0403-8

Henseler, J., Ringle, C. M., \& Sinkovics, R. R. (2009). The use of partial least squares path modeling in international marketing. In New challenges to international marketing (pp. 277-319). Emerald Group Publishing Limited. https://doi.org/10.1108/S1474-7979(2009)0000020014

Hu, L.-t., \& Bentler, P. M. (1999). Cutoff criteria for fit indexes in covariance structure analysis: Conventional criteria versus new alternatives. Structural Equation Modeling: a Multidisciplinary Journal, 6(1), 1-55. https://doi.org/10.1080/10705519909540118

Hulland, J. (1999). Use of partial least squares (PLS) in strategic management research: A review of four recent studies. Strategic Management Journal, 20(2), 195-204. https://doi.org/10.1002/(SICI)1097-0266(199902)20:2<195::AID-SMJ13>3.0.CO;2-7

Järvelä, S., Volet, S., \& Järvenoja, H. (2010). Research on motivation in collaborative learning: Moving beyond the cognitive-situative divide and combining individual and social processes. Educational Psychologist, 45(1), 15-27. https://doi.org/10.1080/00461520903433539

Kaiser, H. F. (1974). An index of factorial simplicity. Psychometrika, 39(1), 31-36. https://doi.org/10.1007/BF02291575

Koopmans, L., Bernaards, C. M., Hildebrandt, V. H., de Vet, H. C., \& van der Beek, A. J. (2014). Measuring individual work performance: Identifying and selecting indicators. Work, 48(2), 229-238. https://doi.org/10.3233/wor-131659

Kubátová, J. (2014). The cause and impact of the development of coworking in the current knowledge economy. In C. Vivas \& P. Sequeiro (Eds.), The Proceedings of the $15^{\text {th }}$ European Conference on Knowledge Management (pp. 571-577). Santarem, Portugal.

Lance, C. E., Butts, M. M., \& Michels, L. C. (2006). The sources of four commonly reported cutoff criteria: What did they really say? Organizational Research Methods, 9(2), 202-220. https://doi.org/10.1177/1094428105284919

Macneil, C. (2001). The supervisor as a facilitator of informal learning in work teams. Journal of Workplace Learning, 13(6), 246-253. https://doi.org/10.1108/EUM0000000005724

Merkel, J. (2015). Coworking in the city. Ephemera, 15(2), 121-139. https://openaccess.city.ac.uk/id/eprint/14478/ 
Merkel, J. (2017). Coworking and innovation. In H. Bathelt, P. Cohendet, S. Henn, \& L. Simon (Eds.), The Elgar companion to innovation and knowledge creation (pp. 570-586). Edward Elgar Publishing. https://doi.org/10.4337/9781782548522.00046

Moilanen, J. (2012). Emerging hackerspaces - peer-production generation. In IFIP advances in information and communication technology: Vol. 378. Open Source Systems: Long-Term Sustainability (pp. 94-111). Springer. https://doi.org/10.1007/978-3-642-33442-9_7

Orel, M., \& Almeida, M. D. M. A. (2019). The ambience of collaboration in coworking environments. Journal of Corporate Real Estate, 21(4). 273-289. https://doi.org/10.1108/JCRE-12-2018-0050

Oxford, R. L. (1997). Cooperative learning, collaborative learning, and interaction: Three communicative strands in the language classroom. The Modern Language Journal, 81(4), 443-456. https://doi.org/10.1111/j.1540-4781.1997.tb05510.x

Parrino, L. (2015). Coworking: Assessing the role of proximity in knowledge exchange. Knowledge Management Research \& Practice, 13(3), 261-271. https://doi.org/10.1057/kmrp.2013.47

Ramli, N. A., Latan, H., \& Nartea, G. V. (2018). Why should PLS-SEM be used rather than regression? Evidence from the capital structure perspective. In Part of the international series in operations research \& management science: Vol 267. Partial least squares structural equation modelling (pp. 171-209). Springer, Cham. https://doi.org/10.1007/978-3-319-71691-6_6

Reio, Jr, T. G., \& Wiswell, A. (2000). Field investigation of the relationship among adult curiosity, workplace learning, and job performance. Human Resource Development Quarterly, 11(1), 5-30. https://doi.org/10.1002/1532-1096(200021)11:1<5::AID-HRDQ2>3.0.CO;2-A

Rus, A., \& Orel, M. (2015). Coworking: A community of work. Teorija in Praksa, 52(6), 1017-1038.

Sarstedt, M., Ringle, C. M., Henseler, J., \& Hair, J. F. (2014). On the emancipation of PLS-SEM: A commentary on Rigdon (2012). Long Range Planning, 47(3), 154-160. https://doi.org/10.1016/j.lrp.2014.02.007

Singh, B., Selvarajan, T. T., \& Solansky, S. T. (2019). Coworker influence on employee performance: A conservation of resources perspective. Journal of Managerial Psychology, 34(8), 587-600. https://doi.org/10.1108/JMP-09-2018-0392

Smith, B. L., \& MacGregor, J. T. (1992). What is collaborative learning. https://www.evergreen.edu/sites/ default/files/facultydevelopment/docs/WhatisCollaborativeLearning.pdf

Spinuzzi, C., Bodrožić, Z., Scaratti, G., \& Ivaldi, S. (2019). "Coworking is about community”: But what is "Community" in coworking? Journal of Business and Technical Communication, 33(2), 112-140. https://doi.org/10.1177\%2F1050651918816357

Tobias, S., \& Carlson, J. E. (1969). Brief report: Bartlett's test of sphericity and chance findings in factor analysis. Multivariate Behavioral Research, 4(3), 375-377. https://doi.org/10.1207/s15327906mbr0403_8

Waters-Lynch, J., Potts, J., Butcher, T., Dodson, J., \& Hurley, J. (2016). Coworking: A transdisciplinary overview. SSRN. https://doi.org/10.2139/ssrn.2712217

Wong, K. K.-K. (2013). Partial least squares structural equation modeling (PLS-SEM) techniques using SmartPLS. Marketing Bulletin, 24(1), 1-32. http://marketing-bulletin.massey.ac.nz/V24/MB_V24_ T1_Wong.pdf 